\title{
REPRESENTASI NASIONALISME DALAM IKLAN KORPORAT PT. GUDANG GARAM TBK
}

\author{
Ria Angelia Wibisono \\ Jurusan Ilmu Komunikasi, Fakultas Ilmu Komunikasi \\ Universitas Kristen Petra \\ Jalan Siwalankerto 121-131 Surabaya 60236 \\ email: ria@yahoo.com
}

\begin{abstract}
Representation of Nationalism in Corporate Advertising of PT. Gudang Garam Tbk. Nationalism is a psychological condition in which somebody surrenders his loyalty to nation state in the name of a nation. While representation is something refers to message, by which reality is encoded in communication; by words, sound, image, or their combination. This thesis explains about how nationalism is represented in the corporate advertising of PT.Gudang Garam Tbk. version "Rumahku Indonesiaku" and "Rumahku Indonesiaku: Cahaya Asa". This is a qualitative research using semiotics method, based on the codes of television theory by John Fiske, syntagm-paradigm concept by Saussure, and the grammar of film and television. The nationalism represented in the advertising consists of self-determination, solidarity, patriotism, social justice, and national identity. Although the advertising is a Corporate Social Responsibility campaign, it still contains particular symbol refers to usual symbol that represents Gudang Garam cigarette product.
\end{abstract}

Keywords: representation, nationalism, corporate advertising, Television semiotics

\section{PENDAHULUAN}

Perkembangan pesat media televisi di Indonesia dewasa ini diikuti dengan meluasnya audiens. Dari fenomena inilah kemudian muncul paradigma bahwa televisi adalah satu-satunya media yang menjamin suksesnya sebuah kampanye (Uway, 2006). Karena itu, iklan televisi pun mengalami peningkatan dari segi kuantitas maupun kualitas. Dalam situs majalah Cakram disebutkan bahwa televisi masih mendominasi perolehan iklan, di mana sekitar 60\% iklan ditampilkan di televisi (Bangkit, 2007). Data Nielsen Media Research ("Perebutan", 2006) menyebutkan, total belanja iklan televisi Indonesia sepanjang tahun 2006 sudah mencapai angka triliunan rupiah. Dari segi kualitas, saat ini sudah banyak iklan televisi yang diproduksi dalam format seluloid seperti halnya film bioskop.

Denis McQuail (1987) menyatakan bahwa media telah menjadi sumber yang dominan untuk memperoleh gambaran dan citra realitas sosial; baik bagi individu, kelompok, maupun masyarakat secara umum. Hukum ini berlaku pula bagi iklan televisi sebagai salah satu sajian media. Di samping itu, iklan televisi pada dasarnya juga merupakan fenomena sosio kultural. Iklan televisi memproduksi realitas dengan mempertimbangkan kenyataan dalam masyarakat. Contohnya, pasca 
tragedi 9/11 di Amerika Serikat, banyak iklan televisi - khususnya jasa penerbangan, investasi, dan pertunjukan teater Broadway - yang menampilkan simbol-simbol patriotisme seperti bendera negara ataupun slogan nasional (Elin dan Lapides, 2004).

Berdasarkan uraian di atas, PT. Gudang Garam Tbk. secara istimewa meluncurkan seri iklan bernafaskan nilai-nilai nasionalisme pada momen-momen tertentu. Iklan pertama, "Rumahku Indonesiaku" diluncurkan pada peringatan kemerdekaan Indonesia di bulan Agustus 2006. Iklan kedua, "Rumahku Indonesiaku: Cahaya Asa" ditayangkan pada pergantian tahun 2006 menuju tahun 2007. Masing-masing iklan kemudian diputar kembali pada momen yang sama di tahun berikutnya. Seri iklan ini dimaksudkan sebagai kampanye Corporate Social Responsibility (CSR).

Penelitian ini merupakan penelitian kualitatif dengan paradigma interpretif konstuktivis. Analisis yang dilakukan adalah analisis representasi. Representasi adalah sesuatu yang merujuk pada pesan yang dengannya realitas disampaikan dalam komunikasi; melalui kata-kata, bunyi, citra, atau kombinasinya (Fiske, 2004). Penggambaran dalam representasi menyangkut tampilan fisik (appearance) dan deskripsi, serta makna (atau nilai) yang ada di baliknya. (Burton, 2007). Representasi dapat diartikan pula sebagai penghadiran kembali (re-presenting) sebuah representasi atau sebuah versi yang dibangun dari gagasan atau objek fisikal asli (Burton, 2007).

Dalam penelitian ini, representasi yang diteliti adalah representasi nasionalisme, yaitu penghadiran versi nasionalisme dalam iklan korporat PT.Gudang Garam Tbk. Secara sederhana, semiotika didefinisikan sebagai bidang studi yang mempelajari makna atau arti dari suatu tanda atau lambang (Sobur, 2004).

Sasaran penelitian adalah tanda dalam iklan korporat PT. Gudang Garam Tbk. versi "Rumahku Indonesiaku" yang berdurasi 120 detik dan versi "Rumahku Indonesiaku: Cahaya Asa" yang berdurasi 180 detik. Tanda ini dapat dilogika melalui kode, yaitu sebuah sistem tanda yang diikat oleh aturan tertentu; di mana aturan dan kesepakatan penggunaannya diinformasikan di tengah anggota suatu budaya. Kode yang akan digunakan dalam penelitian ini adalah kode televisi John Fiske. Dalam level realitas, peneliti memilih kode dress. Pada level representasi, peneliti memilih kode action, camera, music, dialogue, dan setting.

\section{PEMBAHASAN}

Dalam iklan ini, terdapat beberapa simbol yang merepresentasikan bentuk kemandirian dalam usaha memerangi neoliberalisme. Nasionalisme sangat terkait erat dengan kemandirian. Menurut sejarahnya, nasionalisme berawal dari keinginan bangsa-bangsa terjajah untuk menentukan nasib sendiri (self determination). Konsep self determination ini turut mempengaruhi nasionalisme Indonesia (Ong Hok Ham, 2002). Konsep nonkooperasi (tak sudi bekerja sama) dengan penjajah dan berdiri di atas kaki sendiri adalah salah satu pokok pikiran nasionalisme yang lahir dalam masa pergerakan nasional (Ong Hok Ham, 2003). Nasionalisme juga menolak ide kapitalisme global yang memposisikan Indonesia secara terkutuk, yaitu sebagai bangsa paling lembek di muka bumi yang menjadi kulinya bangsa-bangsa lain (Swasono, dalam Maruto dan Anwari, 2003). 
Salah satu konsep kemandirian adalah memenuhi kebutuhan sendiri. Adegan yang mewakili pesan untuk memenuhi kebutuhan sendiri (swasembada) adalah adegan di mana seorang perempuan ditampilkan sedang menumbuk padi. Pada level realitas, kode dress menunjukkan bahwa perempuan yang sedang menumbuk padi itu mengenakan pakaian yang motifnya tampak seperti motif batik tradisional yang dijahit dengan pola modern. Model dan bahan pakaian ini membuat pemakainya bebas bergerak dan tidak kepanasan di tengah hawa musim kemarau. Di samping itu ia juga memakai penutup kepala yang bentuknya seperti semacam sorban, yang membuat rambutnya tertutup dan tidak tergerai kesana kemari. Aksesori yang digunakannya adalah gelang besar yang tidak dikenakan di pergelangan tangan melainkan melekat pada salah satu lengan tepat di atas siku.

Pada level representasi, kode setting menunjukkan, adegan tersebut berlangsung pada pagi hari, bahkan subuh, karena matahari yang terlihat di langit masih berwarna jingga dan letaknya belum tinggi seperti baru saja terbit. Keberadaan matahari yang bisa dilihat dengan kasat mata ini juga menyiratkan bahwa tempat tersebut masih merupakan bagian dari Indonesia. Karena di Indonesia, negara yang tepat berada di garis khatulistiwa, matahari dapat dilihat dan dinikmati sinarnya sepanjang tahun. Kondisi ini berbeda dengan negara subtropis, di mana pada musim-musim tertentu matahari tidak terlihat di negerinya. Bila ditinjau dari konsep paradigma, keberadaan matahari yang menandakan waktu pagi hari ini adalah bagian dari paradigma waktu. Karena, sesuai ciri dasar yang harus dimiliki sebuah unit dalam paradigma, waktu pagi hari memiliki kesamaan karakteristik sekaligus sifat distingtif yang membedakannya dengan waktu siang, sore, ataupun malam hari. Menurut peneliti, pembuat iklan memilih waktu pagi hari dari paradigma waktu dengan maksud tertentu. Waktu pagi hari memiliki konotasi sebagai awal dari hari, dengan matahari yang bersinar di ufuk yang membawa harapan baru.
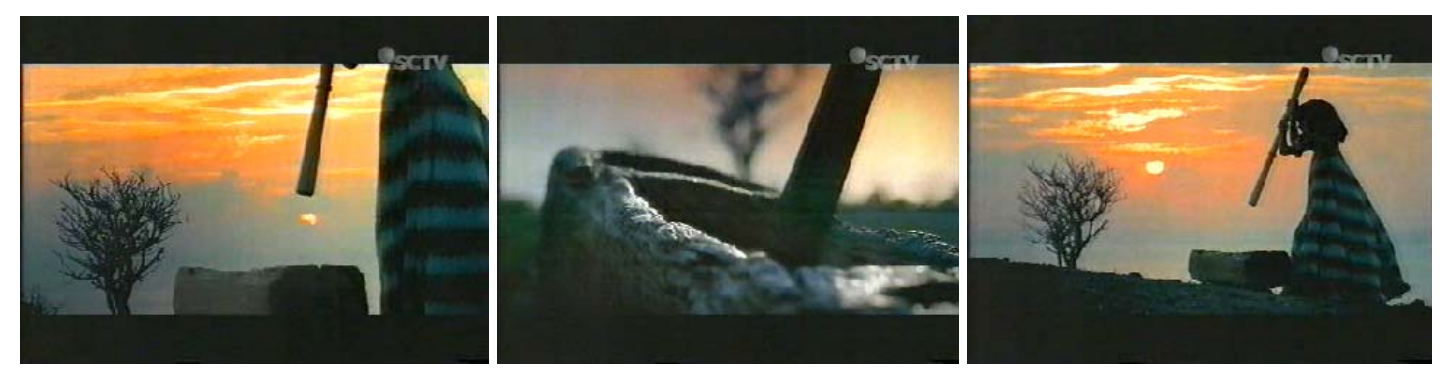

Sumber : Iklan "Rumahku Indonesiaku : Cahaya Asa", scene 4

\section{Gambar 1. Perempuan Menumbuk Padi}

Kode action menunjukkan kegiatan perempuan tersebut yaitu menumbuk padi menggunakan alu dan lesung. Action ini diperjelas oleh kode music, yaitu suara lantunan vokal seorang pria berpadu dengan suara alu yang beradu dengan pemukulnya, menguatkan kesan bahwa action menumbuk padi dengan alu itu dilakukan secara nyata, sehingga bunyi lesung yang dipukul terdengar dengan jelas. Suara dentuman yang keras tersebut menunjukkan betapa besar tenaga yang dikerahkan perempuan tersebut dalam usahanya menumbuk padi, dan mengesankan bahwa padi yang ditumbuk dalam lesung itu sangat sedikit sehingga bunyi 
lesung beradu dengan alu terdengar dominan. Di samping itu masih ada kode camera, yang secara paradigmatik terdiri dari ukuran gambar dan sudut pengambilan gambar. Dari paradigma ukuran gambar, shot pertama menunjukkan gambar dalam ukuran medium shot. Dengan ukuran tersebut, gambar yang terlihat di layar adalah bagian tubuh perempuan dari pinggang ke bawah, tangan perempuan yang memegang alu, lesung, dan sebagian latar belakang pemandangan di belakang perempuan tersebut. Jadi, gambar ini memberi penekanan pada aktivitas yang dilakukan perempuan yaitu menumbuk padi dengan alu.

Dalam shot selanjutnya, gambar lesung dan alu ditampilkan dalam ukuran extreme close up, sehingga alat tersebut terlihat detail dan memenuhi layar. Lesung dan alu jelas ditonjolkan karena setting di belakangnya ditampilkan blur sehingga fokus penonton akan tertuju pada alat-alat tersebut saja. Dari gambar ini pula terlihat bahwa lesung itu tidak terisi penuh dengan padi, bahkan tidak terlihat berkas padi sama sekali. Jadi, padi yang ditumbuk dengan alu itu sedikit sekali sehingga tidak terlihat di layar. Pada shot berikutnya, gambar berukuran long shot, sehingga penonton dapat melihat profil orang yang sedang menumbuk padi tersebut beserta kondisi alam di sekitarnya. Gambar ini memberi kesan paradoks, di mana seorang perempuan terlihat melakukan pekerjaan tani di tengah lingkungan yang tandus dan tidak bisa menghasilkan hasil pertanian yang baik.

Alu dan lesung sendiri adalah alat pertanian Indonesia yang telah ada sejak zaman orang mulai bertani. Usia lesung itu sama tuanya dengan usia budaya tani Indonesia. Hal ini dibuktikan dari kehadiran lesung dalam cerita rakyat Jaka Tarub yang populer di Jawa. Dikisahkan bahwa Dewi Nawangwulan yang menikah dengan Jaka Tarub memiliki kesaktian yang membuatnya mampu menanak nasi langsung dari biji padi tanpa perlu melakukan proses pemisahan kulit padi terlebih dahulu. Akan tetapi pada suatu hari suaminya membuka tanakan nasinya dan menemukan biji padi mentah di dalamnya. Akibat perbuatan itu, kesaktian Dewi Nawangwulan lenyap dan ia harus mengolah padi menjadi beras dahulu sebelum menanaknya menjadi nasi. Akhirnya ia minta kepada Jaka Tarub agar dibuatkan lesung dan alu untuk menumbuk padi. Sejak saat itulah lesung dan alu tercipta (Moelyono, 2003).

Peneliti juga menginterpretasikan sosok perempuan di sini sebagai representasi bangsa Indonesia. Menurut peneliti pemilihan perempuan sebagai tokoh yang melakukan action menumbuk padi dalam adegan ini memiliki makna yang lebih dari sekadar kewajaran bahwa pekerjaan itu memang pekerjaan perempuan. Hal ini terkait dengan salah satu analogi bangsa dalam khazanah bahasa Indonesia, yakni ibu pertiwi. Ben Anderson (1999) dalam karya fenomenalnya "Imagined Communities" menyebutkan bahwa seringkali objek bangsa dituturkan dalam ragam kata yang merujuk pada kekerabatan (ibu pertiwi, vaterland, patria) atau yang mengacu pada rumah (heimat, tanah air). Kedua macam idiom itu digunakan karena manusia selalu terikat pada kerabat dan rumahnya secara alami. Selain itu, dalam beberapa peradaban tertua di dunia, garis kodrati perempuan sebagai ibu yang melahirkan sering diasosiasikan dengan bumi yang menghidupi manusia. Contohnya, dalam mitologi Yunani, dikenal tokoh Dewi Bumi sebagai ibu dari segala sesuatu dan pemelihara atas semua hasil karyanya (Menelaos dan Stephanides, 1991). Sedangkan dalam legenda Cina diyakini bahwa manusia diciptakan dari tanah liat oleh Dewi Nüwa dengan penampilan fisik yang mengacu pada sang dewi (Li, 2003). Dalam budaya Indonesia sendiri, dikenal tokoh Dewi Sri, yang merupakan 
dewi kesuburan yang menciptakan padi sebagai bahan makanan pokok rakyat Indonesia.

Konsep kemandirian yang diangkat dalam iklan ini adalah kontra terhadap neoliberalisme. Neoliberalisme adalah paham yang dibawa oleh arus globalisasi dalam 30 tahun terakhir. Paham ini mendewakan keuntungan materi di atas segalanya dan berusaha menghapus semua tantangan dalam memperoleh keuntungan materi tersebut. Awalan neo (baru) diberikan dalam istilah tersebut karena gejala ini sebenarnya bukan gejala baru. Di akhir abad ke-19 dan awal abad ke-20, liberalisme ekonomi telah mencapai masa kejayaannya, di mana financial capital sangat mendominasi proses ekonomi. Namun, neoliberalisme lebih ekstrim daripada pendahulunya (Herry-Priyono, 2005). Neoliberalisme memberikan peranan yang sangat besar kepada fundamentalisme pasar. Artinya, segala sesuatu diserahkan kepada kemauan dan kekuatan pasar (Tilaar, 2005, dalam Komarudin, 2007). Menurut Bourdieu, seorang sosiolog Prancis (dalam Komarudin, 2007), neoliberalisme masa ini membuat orang-orang yang mencari keuntungan materi menuntut dihapuskannya sistem administrasi dan politik yang dapat mengganggu kelancaran para pemilik modal dalam usaha mencari keuntungan individual yang sebesar-besarnya. Bila perlu, mereka ingin menghapuskan batasan-batasan antar bangsa-negara (nationstate) agar dunia menjadi satu sistem ekonomi global yang bisa dikuasai dengan mudah (borderless world). Dengan demikian, neoliberalisme ini akan mengancam nasionalisme, karena usahanya untuk menghapus batasan-batasan antar bangsa negara tersebut. Bahaya lain neo liberalisme atas negara bangsa adalah neo kolonialisme seperti yang telah dijelaskan di atas.

Peneliti melihat ada alasan tersendiri di balik dominannya ideologi anti liberalisme yang diangkat dalam iklan ini. Di sini PT. Gudang Garam Tbk. ingin memperlihatkan idealisme perusahaannya yang menganut prinsip kemandirian tersebut, sesuai dengan salah satu fungsi iklan korporat yaitu memberi informasi, atau memberi kesan kepada publik sesuai dengan kebijakan, fungsi, fasilitas, tujuan, idealisme, dan standar yang dianut sebuah korporat (Garbett, 1981).

\section{Solidaritas Sosial Melawan Etnosentrisme dan Individualisme}

Solidaritas adalah salah satu modal dasar dalam membangun nasionalisme. Menurut Franz Magnis-Suseno (1992), solidaritas adalah dasar kesatuan sebuah bangsa. Solidaritas berarti sebuah bangsa bergerak maju bersama, membangun kehidupan bangsa atas dasar kesetiakawanan satu sama lain sehingga tidak ada golongan yang tertinggal dibanding golongan lainnya. Senada dengan hal tersebut, Ernest Renan menyatakan bahwa, sebuah bangsa dibentuk oleh kesepakatan atau persetujuan di masa kini, hasrat yang tegas untuk terus mempergunakan warisan kenangan yang diterima secara merata dan tak terpisahkan (Renan, 1994, dalam Hutauruk, 2005). Solidaritas bangsa Indonesia akhirnya dapat membawa bangsa Indonesia menjadi bangsa yang merdeka. Maka, solidaritas bangsa perlu dipertahankan agar tidak terpecah menjadi solidaritas kelompok. Peneliti menemukan bahwa kedua iklan yang diteliti mengangkat konsep solidaritas sosial, yakni solidaritas sosial bangsa Indonesia untuk daerah yang perlu diberi perhatian khusus dan solidaritas dalam bentuk gotong royong sebagai warisan budaya Indonesia. 


\section{Solidaritas Sosial untuk Papua}

Salah satu adegan dalam iklan "Rumahku Indonesiaku" ternyata memuat pesan agar bangsa Indonesia memberi perhatian khusus kepada saudarasaudaranya dari tanah Papua. Pesan tersebut dibungkus dalam adegan di mana sekelompok anak membantu temannya yang memiliki ciri fisik orang Papua untuk mendirikan sebatang kincir bambu.
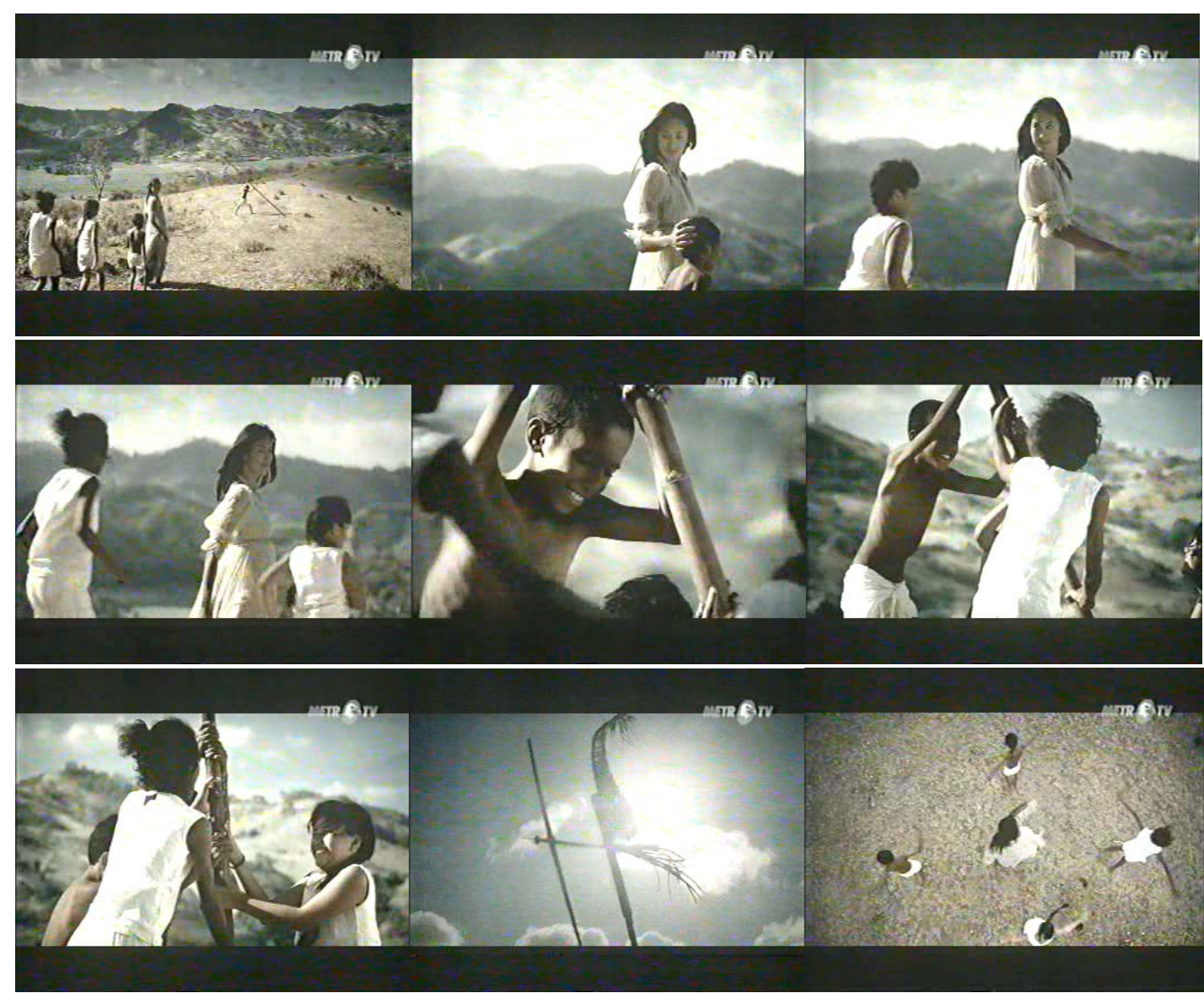

Sumber : Iklan "Rumahku Indonesiaku”, scene 12

\section{Gambar 2. Solidaritas Sosial Papua}

Dalam potongan adegan yang diambil dari iklan "Rumahku Indonesiaku" di atas, terdapat setting berupa padang rumput yang luas. Di latar belakang terlihat perbukitan yang membentang sepanjang gambar tersebut. Antara padang dan bukit terhampar sebuah sungai kecil dengan air yang tenang. Langit dalam kondisi cerah, dihiasi beberapa gumpal kecil awan. Di padang itu tidak banyak terdapat tanaman, selain rumput, belukar, dan sebatang pohon kecil. Setting ini menandakan bahwa daerah tersebut terletak di pedalaman, sehingga tidak ada bangunan apapun di sana. Di samping itu, kondisi alam itu menyiratkan bahwa daerah ini terletak cukup jauh dengan pantai, agak mendekati pegunungan, karena rumput dapat tumbuh dengan baik di tanahnya (tidak seperti tanah berpasir di daerah pantai yang sulit ditumbuhi rumput). 
Secara paradigmatik, kode camera membingkai action dalam adegan ini sedemikian rupa. Pada shot pertama, gambar berukuran extreme long shot. Ukuran gambar ini memperlihatkan seluruh tokoh yang terlibat dalam adegan ini di dalam setting yang mengelilingi mereka. Tokoh-tokoh tersebut antara lain seorang anak laki-laki yang sedang meluruskan bambu di tengah padang, serta seorang perempuan dan tiga anak (dua anak perempuan dan seorang anak laki-laki) yang sedang berjalan mendekatinya.

Secara sintagmatik, peneliti melihat bahwa adegan ini adalah ajakan bagi rakyat Indonesia untuk memperhatikan Papua, seperti yang dilakukan para anak yang membantu temannya yang kesulitan mendirikan kincir bambu seorang diri. Papua memang merupakan merupakan wilayah Negara Kesatuan Republik Indonesia yang perlu diberi perhatian khusus. Sepanjang perjalanannya sering terdengar kabar adanya gerakan separatis di Papua. Bibit-bibit separatisme itu sebenarnya telah tersemai sejak lama. Dilihat dari searah, wilayah Papua merupakan wilayah yang paling terakhir menjadi bagian dari NKRI. Pada tahun 1961, sebenarnya Nicolaas Jouwe dan kawan-kawannya telah memproklamirkan berdirinya negara Papua Merdeka. Namun berkat kejelian Presiden Soekarno memanfaatkan momen Perang Dingin untuk mengambil jalan ekstradiplomatik (18 Desember 1961), Papua kembali ke pangkuan Indonesia pada 1963 (Jacob, 2004).

Bagi bangsa Indonesia sendiri, Papua dijadikan situs keramat dalam pembayangan Indonesia merdeka, melalui slogan dari Sabang sampai Merauke (Anderson, 1999). Namun ternyata, sekalipun mereka menganggap penduduk Papua sebagai 'saudara kandung', ternyata tidak banyak orang Indonesia yang benar-benar mengenal Papua. Benedict Anderson (1999) mencermati bahwa orang Indonesia biasanya hanya melihat orang Irian sebagai 'hantu' yang dinamai menurut petanya, dengan tampilan ragawi negroid, penutup penis yang unik, dan sebagainya.

\section{Keadilan Sosial Melawan Sentralisme Kekuasaan}

Keadilan individual sangat tergantung dari kehendak baik atau buruk masingmasing individu. Tetapi nantinya, keadilan individual ini bisa berbenturan dengan struktur dalam masyarakat. Inilah yang disebut keadilan sosial, yaitu bagaimana pelaksanaan suatu keadilan tergantung dari struktur-struktur kekuasaan dalam masyarakat, baik dalam bidang politik, ekonomi, sosial, budaya, dan ideologi. Membangun keadilan sosial, sesuai cita-cita bangsa Indonesia yang dirumuskan dalam pembukaan UUD 1945 dan sila kelima Pancasila, berarti menciptakan struktur-struktur yang memungkinkan pelaksanaan keadilan (Magnis-Suseno, 1986).

Peneliti menemukan konsep keadilan sosial terepresentasikan dalam iklan "Rumahku Indonesiaku" dalam beberapa scene yang menunjukkan setting peta beberapa daerah di Indonesia. Keempat peta tersebut adalah peta daerah-daerah perbatasan Indonesia. Selain Sabang dan Merauke yang sudah terkenal sebagai situs keramat dalam pembayangan Indonesia merdeka, melalui slogan dari Sabang sampai Merauke (Anderson, 1999), ditampilkan pula Pulau Miangas dan Pulau Dana yang jarang disebut-sebut namanya..

Kompas merilis bahwa (12 Pulau, 2005), dari 92 pulau terluar di Indonesia, ada 67 pulau (28 pulau berpenduduk dan 39 pulau belum berpenduduk) yang berbatasan 
langsung dengan negara tetangga. Pulau Dana dan Pulau Miangas termasuk dalam daftar 12 pulau terluar yang rawan dikuasai secara efektif oleh negara lain. Sebelumnya, tentu rakyat Indonesia tidak akan lupa dengan kasus Pulau Sipadan dan Ligitan yang akhirnya jatuh ke pangkuan Malaysia. Indonesia kalah dengan negara tetangga itu karena Malaysia secara terus menerus berada di pulau itu, melakukan perlindungan dan pelestarian ekologis dan menguasainya secara efektif.

Dari segi ideologi, peneliti membenturkan hasil analisis data di atas dengan teori sentralisme kekuasaan. Sentralisme adalah pemusatan kekuasaan pada pemerintah pusat dengan mengurangi Franz Magnis-Suseno (1992) menyebutkan bahwa setiap kekuasaan dengan sendirinya condong ke arah sentralisme. Setiap desentralisasi kekuasaan biasanya akan mengurangi jangkauan, jumlah, atau bidang keputusan yang dapat diambil oleh penguasa. Dengan demikian, desentralisasi menjadi negatif bila dipandang dari segi penguasa.

\section{KESIMPULAN}

Meskipun iklan ini disebut sebagai kampanye nasionalisme yang merupakan bentuk CSR (Corporate Social Responsibility) PT. Gudang Garam Tbk., iklan ini tidak sekadar memberi kontribusi kepada masyarakat, melainkan juga menguntungkan perusahaan itu sendiri. Salah satunya adalah citra positif sebagai perusahaan yang nasionalis. Selain itu, dalam iklan "Rumahku Indonesiaku: Cahaya Asa", terselip suatu simbol yang identik dengan Gudang Garam, yaitu alat musik terompet yang ditiup seorang perempuan. Terompet adalah alat musik yang selalu hadir dalam iklan PT. Gudang Garam Tbk. sejak era 1990-an hingga sekarang, khususnya untuk produk Surya 16. Secara semiotis, terompet merupakan alat propaganda PT. Gudang Garam Tbk. untuk melawan mitos bahwa merokok merugikan kesehatan terutama mengganggu pernafasan. Terompet adalah alat musik yang sangat membutuhkan pernafasan yang baik. Dalam iklan produk Surya 16 sering ditampilkan seorang pria meniup terompet dengan lancar. Di billboard Surya 16 yang terpasang di jalan raya pun ditampilkan gambar terompet. Munculnya terompet di iklan korporat dengan sendirinya juga akan mengingatkan penonton akan produk Surya 16 milik PT. Gudang Garam Tbk., meski iklan korporat tersebut mengangkat tema nasionalisme. Lagipula, iklan korporat dapat ditayangkan pada jam yang terlarang bagi iklan produk rokok. Padahal, iklan korporat tersebut ternyata tetap mengandung simbol yang identik dengan produk PT. Gudang Garam Tbk.

\section{DAFTAR PUSTAKA}

Anderson, Benedict. 1999. Komunitas-komunitas imajiner: Renungan tentang asalusul dan penyebaran nasionalisme. (Omi Intan Naomi, Trans.) Yogyakarta: Pustaka Pelajar dan Insist Press.

Alnesputra, Maro. 2007. "Yang anda belum tahu soal krisis beras" December 8, Perspektif Online. http://www.perspektif.net/article/article.php? article_id=563

Arifin, Bustanul. 2007. "Ketakutan terhadap bayangan kemiskinan". Kompas Online. http://www.kompas.com/kompas-cetak/0702/19/ UTAMA/3330150.htm 
Aryana, Ida Bagus. 2007, October 17. Personal interview

Bangkit dari keterpurukan. 2007, March 5. March 30, 2007. Cakram Online. http://www.cakram.co.id/cgi-bin/index.cgi?p=014\&id=11

Burton, Graeme. 2007. Membincangkan televisi: sebuah pengantar kepada kajian televisi. (Laila Rahmawati, Trans.) Yogyakarta\& Bandung: Jalasutra.

Chandler, Daniel. 1994. The 'grammar' of television and film. March 12, 2007. Aberyswyth University. http://www.aber.ac.uk/media/Documents/short/ gramtv.html

Cinta Indonesia Magazine. 2006, May 1. Wawancara Amien Rais: "Bongkar kejahatan Freeport”. August 1, 2007. http://cintaindonesiamagazine. blogspot.com/2006_05_01_archive.html

Fiske, John. 1987. Television culture. London and New York: Routledege.

Fiske, John. 2004. Cultural and communication studies. (Yosal Iriantara dan Idi Subandy Ibrahim, Trans.) Yogyakarta\& Bandung: Jalasutra.

Imawan, Riswandha. 1997. Membedah politik Orde Baru: Catatan dari kaki Merapi. Yogyakarta: Pustaka Pelajar

Indonesian Heritage Seri Manusia dan Lingkungan. 2002. Jakarta: Buku Antar Bangsa

Indonesian Heritage Seri Tetumbuhan. 2002. Jakarta: Buku Antar Bangsa

Jacob, Teuku. 2004. Tragedi negara kesatuan kleptokratis: Sebuah catatan di senjakala. Jakarta: Yayasan Obor Indonesia

Juliastuti, Nuraini. 2000, March. Representasi. July 31, 2007. Kunci Cultural Studies Center. http://kunci.or.id/esai/nws/04/representasi.htm

Kompas Online. 2005, March 12. 12 pulau terluar rawan dikuasai negara tetangga. September 7, 2007. http://www.kompas.com/kompas-cetak/0503/12/Fokus/ 1614901.htm

Koentjaraningrat. 1984. Masyarakat desa di Indonesia. Jakarta: Lembaga Penerbit Fakultas Ekonomi Universitas Indonesia

Kumoro, Bawono. 2006, August 16. Nasionalisme Indonesia setelah 61 tahun merdeka. Harian Kompas

Li, Xiaoxiang. 2003. Origins of Chinese folkarts. (Clara H.K., Trans.). Jakarta: Elexmedia Komputindo

Madjowa, Verrianto. 2003, March 17. Miangas, pulau terpencil di ujung Sulawesi. October 13, 2007. Koran Tempo Online. http://www.korantempo.com/news/ 2003/3/17/Nusantara/50.html 
Magnis-Suseno, Franz. 1986. Kuasa dan moral. Jakarta: Gramedia

Magnis-Suseno, Franz. 1992. Filsafat kebudayaan politik: Butir-butir pemikiran kritis. Jakarta:Gramedia

Maruto dan Anwari (eds). 2003. Anak bangsa menggugat: Nasionalisme, kemandirian, dan kewirausahaan. Jakarta: Pustaka LP3ES

McQuail, Denis. 1987. Teori komunikasi massa : Suatu pengantar. (Agus Dharma dan Aminuddin Ram, Trans). Jakarta: Erlangga

Moleong, Lexy J. 1989. Metodologi penelitian kualitatif. Bandung: Remaja Rosdakarya

Ong Hok Ham. 2002. Dari soal priayi sampai Nyi Blorong: Refleksi historis Nusantara. Jakarta: Penerbit Buku Kompas

Ong Hok Ham. 2003. Wahyu yang hilang negeri yang guncang. Jakarta: PDAT.

Perebutan Kue Iklan Tetap Sengit. 2006, December. Cakram Fokus

Renan, Ernest. 1882. What is a nation? (Qu'est-ce qu'une nation?). July 13, 2007. In http://www.tamilnation.org/selfdetermination/nation/ renan.htm

Tamilnation.org.

Sati, Darwis S.N.Sutan. 2006, January. Tafsir pantun minang (3): pantun parasaian. November 13, 2007. Minangkabau Community Portal. http://www.cimbuak. net/content/view/674/46/1/8/

Sobur, Alex. 2004. Semiotika komunikasi. Bandung: Remaja Rosdakarya.

Soekarno. 1933. Indonesia merdeka. Yogyakarta: Kreasi Wacana.

Surbakti, Ramlan. 1992. Memahami ilmu politik. Jakarta: Gramedia

Suwardiman dan Sugihandari. 2007, August 18. Pidato kenegaraan: kegundahan presiden soal nasionalisme. November 6, 2007. Kompas Online. http://www.kompas.com/kompas-cetak/0708/18/Politikhukum/ 3773268.htm

Uway, Judy. 2006, December. Menimbang Efektivitas Televisi. Cakram Fokus

Wiradi, Gunawan. 2007, November 3. Pancasila, pembangunan, dan nasionalisme. November 6, 2007. Rumah Kiri. http://rumahkiri.net/index.php?option= content\&task=view\&id=1390

Waridah, et al. 2003. Antropologi. Jakarta: Bumi Aksara. 